Artigo recebido em

20/03/2014

Aprovado em

$19 / 04 / 2014$

FERNANDA NALON

SANGLARD

Uerj

nandanalon@yahoo.com.br

Jornalista, mestre e

doutoranda em comunicação MARISE BAESSO TRISTÃO

UFF -

marisebaesso@hotmail.com Jornalista, mestre e doutoranda em comunicação
Estudos em Jornalismo e Mídia

Vol. $11 \mathrm{~N}^{\circ} 1$

Janeiro a Junho de 2014

ISSNe 1984-6924

\section{Relatos da ditadura: memórias divulgadas pela imprensa brasileira a partir dos trabalhos da Comissão \\ Nacional da Verdade ${ }^{1}$}

\section{Resumo}

O artigo discorre sobre a construção de uma nova memória acerca da ditadura militar, proporcionada pela instalação da Comissão Nacional da Verdade, em 2012, e pela cobertura midiática sobre as ações do grupo. O movimento iniciado a partir dos trabalhos da comissão demonstra que o Brasil ainda desconhece parte de sua história. Se os produtos jornalísticos contribuem de maneira decisiva para informar a população sobre as coisas do mundo, torna-se fundamental refletir sobre como atuam no processo de divulgação de iniciativa tão relevante para a democracia do país. Por isso, o trabalho se propõe a analisar as reportagens disponíveis nos sites e portais dos principais veículos jornalísticos do Brasil na ocasião da celebração de um ano da instalação da comissão. O intuito é verificar como o jornalismo vem contribuindo (ou pode contribuir) para a construção de novas narrativas sobre o período da ditadura.

Palavras-chave

Memória; ditadura militar; Comissão Nacional da Verdade; Jornalismo.

\begin{abstract}
The article discusses the construction of a new memory about the military dictatorship, provided the facility of the National Truth Commission in 2012, and the media coverage of the commission's actions. The movement started from the work of the committee demonstrates that Brazil still unaware of its history. If journalism contribute in a decisive way to inform people about the things of the world, it becomes essential to reflect on how they act in the disclosure initiative as relevant to the country's democracy process. Therefore, the study aims to analyze the reports available on the websites of major Brazilian journalistic media on the occasion of the celebration of a year of installation of the Commission. The aim is to see how journalism has contributed (can contribute) to construct new narratives about the dictatorship.
\end{abstract}

Keywords

Memory; military dictatorship ; National Truth Commission ; journalism.

1- Uma versão deste artigo foi submetida ao 3o Encontro Regional Sudeste de História da Mídia (Alcar Sudeste). 


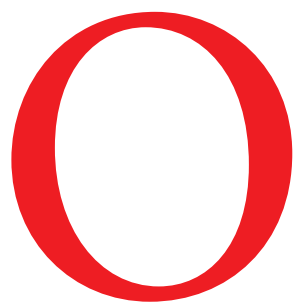

golpe

vivenciado

militar

pelo

Brasil completa 50 anos em 2014.

Ainda que o fato não mereça ser celebrado, também não é algo que deva ser esquecido. $\mathrm{O}$ assunto foi tratado como motivo para se envergonhar, já que o golpe teve amplo apoio de parcelas da sociedade civil, e passou a ser interpretado como algo que não deveria ser comentado e relembrado, ainda que algumas iniciativas fossem desenvolvidas em prol do resgate dessas memórias. Tocar nas feridas do passado não é algo fácil para as sociedades em geral, e não foi fácil também para o Brasil, que apenas em 2012 viu concretizar o projeto de uma comissão da verdade em âmbito nacional.

Em 1984 a população já tomava as ruas na campanha pelas "Diretas Já", e também por mais liberdade e mais transparência dos órgãos públicos. Mas mesmo após a abertura política, iniciada em 1979 e tendo como marco o ano 1985, e o princípio do reestabelecimento democrático, os brasileiros ainda se viram diante da falta de acesso à informação pública e da dificuldade de conhecer seu passado. Até hoje famílias convivem com dúvidas sobre parentes tidos como desaparecidos políticos, sem saber o paradeiro dos familiares e sem poder enterrar seus corpos. Milhares de documentos perdidos - ou

2- Slogan das iniciativas populares que lutavam pelo voto direto para a Presidência da República.

3- Lei 12.527 foi sancionada em 18 de novembro de 2011, mas entrou em vigor seis meses depois, em maio de 2012. escondidos - ainda encobrem momentos não esclarecidos e mascaram atos de graves violações dos direitos humanos respaldadas pelas forças de Estado.

Ainda que o Brasil seja o país do Cone Sul que tenha o maior acervo documental de origem pública sobre a repressão política (Stampa; Sá Netto, 2013), sabe- se que o acesso a esse material, por meio da abertura e divulgação dos principais arquivos, ocorreu de forma lenta e até mesmo tardia, tendo se ampliado apenas depois da Lei de Acesso à Informação ${ }^{3}$, que entrou em vigor em 2012. A partir da iniciativa, os órgãos públicos dos três poderes, bem como autarquias, fundações e empresas públicas passaram a ter a obrigação de divulgar as prestações de contas, gastos com pessoal - incluindo salários de servidores - bem como documentos públicos solicitados por qualquer cidadão.

Foi também nos últimos anos que se viu implementar a maioria das comissões da verdade locais e que o país começou a destrinchar a própria história e alterar algumas memórias até então predominantes. A partir dessas ações, a divulgação da informação pública passou a ser norma, sendo considerado exceção o segredo, que até então era tido como regra.

É diante deste novo cenário que a Comissão Nacional da Verdade (CNV) celebrou um ano de atividades em maio de 2013 e divulgou um relatório parcial dos levantamentos realizados até o momento. Sabendo que grande parcela da população teve e ainda tem acesso aos trabalhos da comissão a partir dos relatos da imprensa, e não pela busca direta ao órgão, a proposta deste artigo é avaliar como os veículos de mídia brasileiros noticiaram assuntos relativos à $\mathrm{CNV}$ na semana em que a comissão completou um ano. Os desdobramentos do golpe de 1964 receberam destaque? As notícias privilegiaram os resultados do relatório ou a avaliação do primeiro ano da comissão? Quais dados do relatório foram destacados? A disputa pela memória - 
travada entre vítimas e perpetradores foi abordada? Quais os enquadramentos predominantes?

Para responderaessesquestionamentos, recorre-se à análise de conteúdo e de enquadramento com o intuito de verificar como o jornalismo vem contribuindo (ou pode contribuir) para a construção de novas narrativas sobre o período da ditadura.

\section{O que é uma comissão da verdade?}

No livro "Unspeakable Truths", Priscilla Hayner (2011) faz um amplo apanhado das comissões da verdade estabelecidas em todo o mundo entre 1974 e 2009. A autora identifica 40 iniciativas, sendo que 21 delas foram criadas na primeira década do século XXI, demonstrando como esse é um processo recente.

Essas 21 comissões mais recentes abrangem todas as regiões do mundo e uma grande variedade de contextos políticos: oito das Américas, sete na África, cinco na Ásia e uma na Europa. A primeira comissão da verdade foi concluída no mundo árabe, com audiências públicas televisionadas e levando a extensa reparação. Duas dessas comissões foram criadas na América do Norte. Três das cinco comissões que julgo serem as mais fortes até agora operaram nesta década. (Hayner, 2011: xiv, tradução nossa $)^{4}$.

As cinco comissões consideradas "mais fortes" por Hayner são a Comissão da Verdade e Reconciliação que funcionou na África do Sul entre 1995 e 2002, a Comissão para Esclarecimento Histórico da Guatemala (1997-1999), a Comissão da Verdade e Reconciliação do Peru (2001-2003), a Comissão de Acolhimento, Verdade e Reconciliação do Timor-Leste
(2002-2005) e a Comissão de Equidade e Reconciliação de Marrocos (2004-2006). Mas a autora também confere destaque ao trabalho de outros grupos, como as duas experiências do Chile e também as comissões da Argentina, de El Salvador e da Alemanha, entre outras. A comissão da verdade brasileira - por ter sido criada em 2011 pela Lei 12.528 e instituída apenas em 2012 - não entrou na contabilidade das 40 levantadas pela autora.

O foco da Comissão Nacional da Verdade $(\mathrm{CNV})$ - nome recebido pelo órgão no Brasil - é apurar os casos de violações dos direitos humanos ocorridos entre 1946 e 1988, o que inclui o período da ditadura militar. Inicialmente, a CNV teria exatos dois anos de atuação, mas o prazo foi prorrogado e a comissão passou a ter até o fim de 2014 para concluir o relatório. A partir de recolhimento de depoimentos orais e de pesquisas

\section{Mesmo após a abertura política, os brasileiros ainda se viram diante da falta de acesso à informação pública}

realizadas em arquivos - muitos deles até então fechados à consulta -, o grupo de trabalho pretende promover a responsabilização não-penal pelos crimes ocorridos durante o regime de exceção e contribuir para a divulgação de fatos ainda obscuros.

De acordo com o livro-documento Direito à Memória e à Verdade,
4- "These twentyone most recent commissions span all regions of the world and a wide range of political contexts: eight in the Americas, seven in Africa, five in Asia, and one in Europe. The first truth commission was concluded in the Arab world, featuring televised public hearings and leading to extensive reparation. Two of these commissions were created in North America. Three of the five commissions that I judge to be the strongest to date have operated in this decade." 
5- Angel Manfredo Velásquez Rodríguez era estudante

da Universidade

Nacional Autônoma

de Honduras

quando foi detido,

de forma violenta e

sem a apresentação

de ordem judicial

de captura, pela

Direção Nacional

de Investigação e do

G-2 (Inteligência)

das Forças Armadas

de Honduras. A

detenção ocorreu em

Tegucigalpa, em 12

de setembro de 1981.

Os denunciantes

declararam que o

jovem fora levado

junto com outros

detidos para as celas

da II Estação da

Força de Segurança

Pública, localizadas

no Bairro El Manchén

de Tegucigalpa,

onde foi submetido

a interrogatórios,

torturas e acusado de

delitos políticos. As

corporações policiais

e de segurança

negaram a detenção

do estudante e ele

desapareceu, sem

que a família tenha

tido acesso ao

paradeiro do rapaz

ou à localização

de seu corpo.

(JURISPRUDÊNCIA,

1988).

6- "The first clear

legal ruling on this

was by the Inter-

American Court of

Human Rights in the

Velasquez Rodriguez

case of 1988, where

it was confirmed that

the state hás a duty

to investigate the fate

of the disappeared

and disclose the

information to

relatives."

7- Hoje o órgão

chama-se Conselho

de Direitos Humanos

das Nações Unidas.

54 elaborado pelo governo federal, há 150 casos de opositores do regime militar que desapareceram após serem presos ou sequestrados por agentes do Estado. Não há registro da prisão deles em nenhum tribunal ou presídio, os advogados não foram notificados e os familiares até hoje procuram esclarecimentos sobre onde estão os corpos das vítimas. Em 2010, o Brasil foi condenado na Corte Interamericana de Direitos Humanos da OEA em ação movida por familiares de mortos e desaparecidos na Guerrilha do Araguaia (...). (COMISSÃO NACIONAL DA VERDADE, 2012).

Conforme Hayner, é justamente a ação de órgãos internacionais em prol dos direitos humanos que tem cobrado e motivado o desenvolvimento de muitas comissões da verdade pelo mundo. Investigar e tornar públicas as violações dos direitos humanos cometidas no passado por agentes do Estado começou a ser algo interpretado pelas cortes internacionais como obrigação dos países. Tal procedimento tem sido reafirmado por documentos e resoluções voltadas para políticas públicas. "A primeira decisão jurídica clara sobre isso foi dada pela Corte Interamericana de Direitos Humanos no caso Velásquez Rodríguez ${ }^{5}$, em 1988, em que foi confirmado que o Estado tem o dever de investigar o destino dos desaparecidos e divulgar as informações aos parentes", (HAYNER, 2011: 24, tradução nossa ${ }^{6}$ ).

Relatório aprovado pela Comissão das Nações Unidas sobre Direitos Humanos afirma o direito inalienável de conhecer a verdade sobre os acontecimentos passados e de que as vítimas e suas famílias sejam informadas sobre as circunstâncias em que ocorreram as violações.

Enquanto o relatório observa que as sociedades podem se beneficiar de uma comissão da verdade, ele deixa claro que qualquer decisão de criar tal comissão, ou para definir seus termos e composição, "deve ser baseada em amplas consultas públicas em que os pontos de vista das vítimas e sobreviventes especialmente são procurados". (HAYNER, 2011: 24, tradução nossa $\left.{ }^{8}\right)$.

Segundo Hayner (2011:10), a primeira comissão da verdade amplamente conhecida foi criada na Argentina em 1983, mas esse órgão não era referenciado como uma "comissão da verdade" naquela época, sendo chamado de Comissão Nacional de Desaparecidos - Conadep. Conforme a autora, o título "comissão da verdade" surgiu quase dez anos mais tarde, com a Comissão Nacional de Verdade e Reconciliação do Chile e a Comissao da Verdade de El Salvador, concluídas em 1990 e 1992, respectivamente.

Diante de muitas dúvidas sobre o que pode ou não ser considerado como comissão da verdade, bem como sobre quais são suas atribuições, retornamos ao levantamento feito por Priscilla Hayner (2011), que, entre tantas qualidades, oferece algumas das mais esclarecedoras definições. A acepção sugerida pela primeira vez pela autora, em 1994, ainda é frequentemente citada, embora ela mesma admita que tenha algumas limitações. A ideia essencial era definir uma comissão da verdade como um grupo de trabalho focado no passado, criado para investigar um padrão de abusos durante um período de tempo, em vez de um evento específico, instituído como um órgão temporário, com a intenção de concluir as atividades com um relatório público, e oficialmente autorizado ou habilitado pelo Estado.

Mas Hayner pondera que o analista 
jurídico Mark Freeman conseguiu sugerir um conjunto mais detalhado de qualificadores, ao propor também mais dois elementos. Segundo ele, uma comissão da verdade se concentra em atos graves de violência ou repressão (sendo que esses atos ocorreram em períodos recentes de regime abusivo ou conflito armado), descreve as causas e consequências das violações e investiga violações cometidas pelo Estado ou por seus agentes. Ele frisa que, apesar de a própria comissão se basear nesse Estado, deve manter independência para que possa se concentrar nas vítimas.

Freeman (apud Hayner, 2011) também sugere outro ponto de análise para determinar o que é realmente uma comissão da verdade, que seria a percepção pela população local (e até mesmo global). Contudo, Hayner considera que, apesar de útil, o critério é subjetivo e pode ser limitante. A autora destaca ainda que outros analistas acrescentaram apenas um elemento em sua descrição feita em 1994, que seria o fato de uma comissão da verdade sempre se envolver com vítimas e sobreviventes. "Finalmente, alguns têm sugerido que todas as comissões da verdade têm a intenção explícita de avançar na reconciliação ou até mesmo a construção da democracia." (HAYNER, 2011: 11, tradução nossa ${ }^{9}$ ). Mas Hayner defende que o essencial sobre as comissões da verdade é o propósito de afetar a compreensão social e a aceitação do passado do país. Portanto, ela afirma que:

(...) a intenção das comissões da verdade é parte do que as define: de abordar o passado, a fim de mudar as políticas, práticas e até mesmo relacionamentos no futuro, e para fazê-la de uma forma que respeite e honre aqueles que foram afetados pelos abusos. Isso pode ser capturado na seguinte definição ligeiramente revisada: A comissão de verdade (1) está focada no passado dos eventos, em vez dos em curso, (2) investiga um padrão de acontecimentos que tiveram lugar durante um período de tempo, (3) se envolve diretamente e amplamente com a população afetada, coletando informações sobre as suas experiências; (4) é um órgão temporário, com o objetivo de elaborar um relatório final, e (5) é oficialmente autorizada ou habilitada pelo Estado sob revisão. (HAYNER, 2011: 11-12, tradução nossa $\left.{ }^{10}\right)$.

Acrescentamos a essa revisão proposta por Hayner a categoria descrita por Freeman relativa à função de apurar atos de violência ou repressão. É importante também frisar que uma comissão da verdade se distancia de um órgão governamental de direitos humanos, ainda que sua intenção também seja defender esses direitos. Difere-se ainda dos órgãos de investigação do Judiciário, que, normalmente, têm intuito de esclarecer fatos relativos a eventos específicos e separadamente.

Há muitas nomenclaturas para se referir ao que aqui chamamos genericamente de comissões da verdade. "Comissão sobre desaparecidos", "comissão de verdade e justiça", "comissão da verdade, justiça e reconciliação", "comissão de esclarecimento histórico", "comissões de verdade e reconciliação", são apenas alguns exemplos. E, embora esses grupos de trabalho tenham muito em comum, Hayner (2011: 12) alerta para o fato de os mandatos e poderes de investigação específicos diferirem consideravelmente, "refletindo as necessidades, possibilidades e realidades políticas de cada país". Mas
8- While the report notes that societies may benefit from a truth commission, it makes clear that any decision to establish such a commission, or to define its terms and composition, "should be based upon broad public consultations in which the views of victims and survivors especially are sought".

9- "Finally, some

have suggested that all truth commissions have the explicit intention to advance reconciliation or even democracybuilding."

10- "(...) the intention of truth comissions is part of what defines them: to adress the past in order to change policies, practices, and even relationships in the future, and to do so in a manner that respects and honors those who were affected by the abuses. This can be captured in the following slightly revised definition: A truth comission (1) is focused on past, rather than ongoing, events; (2) investigates a pattern of events that took place over a period of time; (3) engages directly and broadly with the affected population, gathering information on their experiences; (4) is a temporary body, with the aim of concluding with a final report; and (5) is officially authorized or empowered by the state under review". 
também existem instituições ganhando o nome de comissão da verdade sem ter qualquer semelhança com os ideais expostos anteriormente.

Cabe destacar que o que chamamos de comissão da verdade vai além de um grupo de trabalho que busca encontrar e dizer a verdade sobre abusos do passado. Em muitos contextos, essa se tornou a iniciativa mais importante dos governos para lidar com memórias que não ganhavam espaço no debate público, responsabilizar os violadores, reparar as vítimas e propor reformas.

Por isso, Hayner (2011: 20, tradução nossa ${ }^{11}$ ) define que o primeiro e mais concreto objetivo de uma comissão da verdade é destinado à averiguação: "estabelecer um registro preciso do passado de um país, esclarecer eventos incertos, e levantar a tampa do silêncio e da negação de um período controverso e doloroso da história”.

\section{A mídia valoriza determinados aspectos e fatos,}

11- "(...) to establish an accurate record of a country's past, clarify uncertain events, and lift the lid of silence and denial from a contentious and painful period of history".

12- "(...) rarely reported honestly in the press, and certainly out of bounds for the official history taught in schools. In effect, the report of a truth commission reclaims a country's history and open it for public review".

\section{encuanto silencia \\ outros}

Para a autora, o reconhecimento importante para efetivamente quebrar o silêncio de um tema que antes era só susurrado, e por muito tempo foi considerado perigoso ou sigiloso, "raramente relatado honestamente na imprensa, e, certamente, fora dos limites da história oficial ensinada nas escolas. Com efeito, o relatório de uma comissão oficial e público de abusos do passado é da verdade recupera a história de um país e abre-a para revisão pública”. (HAYNER, 2011: 20, tradução nossa ${ }^{12}$ ).

$\mathrm{O}$ enfoque nas vítimas é outro ponto que merece ser destacado, contrariando a expectativa de setores da sociedade - principalmente agentes do Estado envolvidos nas violações ou infrações e parcelas da população que apoiaram as ditaduras e os regimes totalitários, por exemplo - de que a comissão da verdade também apure atos de violência cometidos pela sociedade civil em resposta à repressão.

Essas cobranças, no entanto, partem de quem não compreende um dos objetivos da comissão, que está atrelado aos atos cometidos pelas forças do Estado.

Por isso, as comissões da verdade se dedicam a ouvir as memórias das vítimas, realizar audiências públicas e divulgar relatório que descreva as experiências de sofrimento, os locais onde as violações ocorreram, as causas de morte e correções de atestados de óbitos (muitas vítimas foram assassinadas e as famílias precisam conviver com atestados de suicídio). Essa é uma forma de cobrar responsabilidade institucional (normalmente das polícias, dos militares e do sistema judicial), recomendar ações para responsabilização criminal e incentivar a reconciliação.

\section{A responsabilidade da imprensa}

Apesar de todo o engajamento das comissões da verdade para ouvir a sociedade e divulgar os resultados das investigações, a maioria da população não tem acesso a esse material diretamente, mas sim por intermédio da imprensa, que fornece atalhos para que o cidadão se informe sobre o mundo. 
São as notícias que tornam o complexo e desordenado mundo no qual vivemos menos caótico para cada um de nós, que nos ajudam a selecionar, priorizar, organizar, compreender e ordenar os acontecimentos de nossa realidade imediata. Lemos, ouvimos e vemos as notícias diariamente porque elas orientam primordialmente a nossa vida prática, os nossos comportamentos, as nossas preferências, os nossos gostos, as nossas decisões de todo tipo. As notícias são, assim, experiências diárias de conhecimento prático primordial e essencial para os indivíduos nas sociedades contemporâneas (MOTTA, 2002: p. 2).

Ao fornecer atalhos para o público, a mídia também valoriza determinados aspectos e fatos, enquanto silencia outros, contribuindo assim para a formação de determinada memória e enquadramento sobre os assuntos. É importante ressaltar ainda que o jornalista se coloca e se justifica como o instrumento que vai trazer a verdade dos fatos para o mundo, portanto, muitas vezes, é ele quem constrói a versão que ficará para a história.

Ao considerar o golpe de 1964 como um "evento-chave na construção de sentidos para as últimas décadas e para a atualidade política, participando da composição da temporalidade que orienta o fazer e o representar social e político", Flávia Biroli (2009: 269) propõe que a mídia pode ser abordada - pelo menos - de duas maneiras em relação a esse contexto. A primeira é como instituição que contribui sobremaneira para os processos de significação nas sociedades contemporâneas. A segunda maneira é referente à atuação no cenário que culmina com o golpe, a ditadura e a democratização "de forma não-

homogênea e não-determinada".

Denise Rollemberg (2010), ao vasculhar documentos e trabalhos acadêmicos em busca dos apoiadores civis ao golpe, destaca o papel por vezes contraditório da Associação Brasileira de Imprensa (ABI), que no discurso era contrária à censura e a favor da liberdade de imprensa, mas na prática tinha líderes que mantinham proximidade com os ministros militares, vindo inclusive a assumir cargos no governo.

A ABI, como instituição, não apoiou, formalmente, o golpe. Entretanto, na leitura das Atas das Reuniões Ordinárias e Extraordinárias e do Boletim do Conselho Administrativo da ABI, chama a atenção o tipo de luta encaminhado: eminentemente corporativa, de defesa de jornalistas presos e da liberdade de imprensa. Evidentemente, eram pontos de pauta de grande importância na chamada resistência democrática, mas estavam longe de esgotar a agenda de temas que se impunham, mesmo - ou sobretudo - numa instituição de jornalistas. Assim, muitas vezes, é a ausência de determinados temas o que chama a atenção, prevalecendo em debate outros menos relevantes diante do contexto por que o país passava (ROLLEMBERG, 2010: 104).

A contradição observada na ABI também podia ser vista nas redações, que tinham funcionários e chefes atuando dos "dois lados" do processo. Mesmo que grande parte dos jornais comerciais da época tenha apoiado o movimento golpista, é inegável que a imprensa foi alvo de censura. Contudo, a maneira como os atos de cerceamento atingiram cada empresa de mídia não foi equânime. Até mesmo porque há diferenças entre os 
vários tipos de mídia. Jornais regionais e outros tipos de mídia, como o rádio, por exemplo, muitas vezes, estiveram e estão nas mãos de oligarquias locais que os utilizam para solidificar seu controle político.

Biroli (2009: 278) acrescenta que o envolvimento dos jornais e dos jornalistas com a queda de governantes, como Getúlio Vargas (em 1954) e João Goulart (em 1964), resultou em silêncio ou valorização de algumas memórias em detrimento de outras.

Silenciam, assim, sobre o fato de que as relações entre imprensa e política em tempos de democracia se caracterizaram, inúmeras vezes, por práticas negadoras de aspectos centrais à política democrática, como a não aceitação das opções contidas no voto, a não aceitação do confronto como constitutivo da política e das sociedades e, para fazer uma referência explícita às discussões em Koselleck e D’Allones, a não aceitação da indeterminação que constitui a política e a democracia. (BIROLI, 2009: 278).

É importante ressaltar o comportamento na imprensa e não só da ABI naquele momento. Waisbord (2000) destaca a proximidade da imprensa com o governo militar após a deposição de João Goulart.

No Brasil, a imprensa, em princípio, manteve uma relação de proximidade com o governo, após a deposição de João Goulart, em 1964. Isso porque os principais jornais haviam colaborado ativamente com o golpe. Depois, o governo mudou as engrenagens e decidiu silenciar a imprensa (e a sociedade em geral), fechando o Congresso e eliminando os direitos democráticos, em dezembro de 1968. Esta decisão marca o início da fase "dura" do regime autoritário. Quinze jornalistas foram torturados até a morte ou desapareceram entre 1970 e 1978. Os censores foram removidos depois de 1975, quando a fase mais brutal e repressiva da ditadura terminou e começou o processo gradual de abertura política com a vinda do general Ernesto Geisel ao poder (WAISBORD, 2000, p. 23).

Ainda segundo Waisbord, o Correio da Manhã, único jornal de grande público creditado por ter feito forte oposição à ditadura militar (apesar dos famosos e polêmicos editoriais publicados em março e abril de 1964 que pediam que Jango entregasse o governo), perdeu uma quantidade substancial de publicidade, ao ter resistido às pressões de grandes patrocinadores para mudar sua posição editorial.

Já nas décadas de 1960 e 1970, jornais como O Estado de São Paulo, Jornal do Brasil e Tribuna da Imprensa ocasionalmente fazem críticas ao regime autoritário e até mesmo desenvolvem investigações de casos que envolviam servidores do governo. No entanto, o chamado "jornalismo cão de guarda" continua a ser uma exceção. Alem, é claro, da imprensa alternativa, a qual, muitas vezes, sobreviveu na clandestinidade.

No cenário atual marcado pela ampliação dos direitos e liberdades e pela diversificação e crescimento dos mais diversos tipos de mídias, principalmente no campo digital, os veículos jornalísticos voltam a se deparar com a temática da ditadura militar não apenas nas datas celebratórias e/ou midiáticas (como os 30 anos das "Diretas Já" ou os 50 anos do golpe de 1964), mas cotidianamente a partir dos novos achados feitos pela CNV e pelos trabalhos de inúmeras organizações não governamentais e comissões da verdade 
que contribuem com o movimento de resgate desse período da história.

Assim, a imprensa, que nos anos de ditadura passou distante de ser um ator neutro, tem uma nova possibilidade de recontar as narrativas que na ocasião não ganharam espaço ou foram censuradas. Lembrando aqui o papel de ator social desta imprensa, importante definidora de sentidos e também influenciadora da opinião pública. Portanto, o que se pretende neste artigo é demonstrar, a partir de um caso específico (a divulgação do relatório de um ano de atividades da $\mathrm{CNV}$ ), a forma como esse resgate vem sendo feito.

\section{Um novo olhar sobre os atos da ditadura?}

A partir do acesso ao clipping diário produzido pela Assessoria de Comunicação da CNV, esta análise leva em consideração as matérias que constam no material produzido entre 15 e 22 de maio de 2013. Justificam-se tais datas pelo fato de a CNV ter completado um ano no dia 16 e divulgado o balanço de atividades no dia 21, portanto, o período selecionado abarca um dia antes e um dia depois dos eventos.

Das 87 matérias (o que inclui notas, notícias, reportagens e entrevistas) relativas a grupos de mídia presentes no clipping, foram consideradas apenas as oriundas de veículos de circulação - ou abrangência - nacional (portais, periódicos, rádios e telejornais) com presença na internet e cujos links das matérias permanecem ativos, o que resultou corpus com 64 matérias (23 foram excluídas por não atenderem os critérios acima).
TABELA 1:

\begin{tabular}{|ll|}
\hline Temas abordados & $\mathrm{n}^{\circ}$ matérias \\
\hline Possível julgamento de torturadores / revisão anistia & 10 \\
\hline Balanço das atividades & 7 \\
\hline Ex-militar relata execução de militantes & 6 \\
\hline Relatório 1 ano - Marinha ocultou documentos & 6 \\
\hline Relatório 1 ano - tortura nos primeiros anos & 5 \\
\hline Abordagens sobre outras comissões (MG e UNB) & 4 \\
\hline Militares recusam colaborar & 3 \\
\hline Especulação sobre relatório de 1 ano & 3 \\
\hline Exumação de Jango & 3 \\
\hline Prorrogação CNV & 2 \\
\hline Crítica ao formato dos trabalhos da CNV & 2 \\
\hline Relatos de vítimas & 2 \\
\hline Posicionamento divergente entre Governo e Comissão & 2 \\
\hline CNV e Lei de Acesso à Informação & 1 \\
\hline Anistia Internacional sugere depoimento público de Dilma & 1 \\
\hline Militares criticam comissão & 1 \\
\hline Familiares pedem investigação & 1 \\
\hline Explicações sobre o que faz a comissão & 1 \\
\hline Dificuldades impostas ao trabalho da CNV & 1 \\
\hline Relatório 1 ano - geral & 1 \\
\hline Relatório 1 ano - Universidades foram centros de tortura & 1 \\
\hline Reparação de vítimas e familiares & 1 \\
\hline
\end{tabular}

Fonte: Clipping CNV/Levantamento da autora

Por meio de instrumentos da análise de conteúdo $^{13}$, as 64 matérias foram categorizadas conforme os temas predominantes. Assim, foi possível distribuí-las em 22 assuntos (conforme a tabela 1 demonstra). Entre os temas mais abordados pela imprensa nas datas em questão estão a possibilidade de que o relatório final da $\mathrm{CNV}$ indique punição ou abertura de processo contra agentes do Estado que violaram os direitos humanos e futura revisão da lei de anistia em vigor no país. Dez matérias abordaram tal tema, sendo que outras duas, focadas 
13- Método de análise desenvolvido nos

Estados Unidos na primeira metade do século XX com foco, principalmente, em pesquisas de opinião pública e propaganda política. Após período de descrença e críticas em relação à aplicação extremamente quantitativa, o método foi sendo aperfeiçoado e hoje é compreendido como técnica que parte de dados para formular inferências. Segundo uma das principais teóricas da Análise de Conteúdo, Lawrence Bardin (2008), o debate entre as abordagens quantitativa e qualitativa foram de alguma forma superados a partir do aperfeiçoamento teórico. "A análise de conteúdo aparece como um conjunto de técnicas de análise das comunicações que utiliza procedimentos sistemáticose objetivos de descrição do conteúdo das mensagens." (BARDIN, 2008, p.40). Atualmente, a tendência da análise de conteúdo não prevê a dicotomia entre quantitativo e qualitativo, mas sim a integração entre as duas possibilidades.

14- A partir do conceito de enquadramento desenvolvido por Goffman (2012), avançou-se também a ideia de enquadramento de mídia, ou enquadramento noticioso (news framing). O termo se refere aos modelos de interpretação e seleção que definem aquilo que será destacado ou excluído, com o intuito de organizar o discurso. Todd Gitlin (1980) e Robert Entman (2012) são alguns dos autores que aprofundam os estudos da relação entre enquadramento $e$ jornalismo. no posicionamento divergente entre a comissão e o Governo federal também envolveram a temática, já que foram motivadas pelo fato de o ministro da Defesa, Celso Amorim, ter contrariado a fala de membros da CNV que defendem a revisão da lei de anistia, afirmando que o Governo não tem essa proposta.

Também entre os assuntos mais destacados estão as reportagens que, aproveitando-se do calendário celebratório, realizaram balanços sobre os trabalhos da comissão ou repercutiram o relatório de um ano de atividades divulgado no dia 21 de maio de 2013. Se forem somadas todas as matérias que adotaram esse gancho noticioso, elas assumem a dianteira, totalizando 20 matérias veiculadas no período. Contudo, separamos aqui os desdobramentos proporcionados pela divulgação do relatório. Assim, houve uma reportagem que abordou o relatório de forma geral; uma que focou as universidades onde houve tortura; cinco que destacaram o fato de a tortura ter ocorrido desde os primeiros anos do regime - contrariando pensamento recorrente de que tinha sido praticada apenas após 1968 e a publicação do ato institucional n5 (AI5); e seis notícias veiculadas tendo como mote outra revelação do relatório: de que a Marinha ocultou documentos solicitados por órgãos governamentais. $\mathrm{O}$ restante (7 matérias) foi relativo a balanços gerais de um ano de trabalho da CNV (ver Tabela 1).

Mas mais importante do que a quantidade de matérias veiculadas, é o enquadramento ${ }^{14}$ que elas privilegiaram. A partir da leitura minuciosa dos textos e da aplicação prévia de ferramentas da análise de conteúdo, é possível afirmar que, em geral, as matérias seguiram os valores-notícia ${ }^{15}$ tradicionais, como notoriedade, proximidade, notabilidade, inesperável e controvérsia. Todos esses elementos podem ser percebidos (não necessariamente simultaneamente) nas reportagens, entrevistas e notícias sobre a Comissão da Verdade, mas é a forma como o discurso é organizado, aquilo que é destacado ou silenciado nos textos que nos interessa. Por isso, o valor-notícia que mais se destaca nas matérias é o relativo ao fator “tempo". Isso porque acontecimentos que já tiveram repercussão em outros momentos voltam a ser noticiados (como a morte de Jango, a partir da exumação solicitada pela CNV), servindo para que novas discussões entrem na pauta. E o fator tempo, frequentemente

\section{O enquadramento} que privilegiam é mais relevante que a quantidade de matérias veículadas

determinante daquilo que será noticiado quando eventos ou empreendimentos "completam aniversário", pode ser considerado fundamental para justificar que houvesse amplificação dos temas relativos à $\mathrm{CNV}$ nos noticiários.

Mas foi graças a um "evento-midiático" proporcionado pela divulgação do relatório de um ano de atividades juntamente com as revelações que esse balanço trouxe - que parte significante das notícias (30 das 64 analisadas) foi publicada nos dias 21 e 22 de maio e não no dia 16 , data que marcou um ano 
de instituição da comissão (quando dez notícias foram publicadas).

Em relação aos veículos que constavam no clipping, das 64 matérias que integram o corpus da análise, 18 foram veiculadas pelos impressos Folha de S.Paulo e O Globo (sendo nove de cada veículo) e em suas respectivas páginas na internet. Os dois, seguidos do também impresso O Estado de São Paulo (com oito matérias) foram os que mais publicaram notícias envolvendo a CNV no período mencionado. A Agência Brasil, agência de notícia pública que integra a Empresa Brasil de Comunicação (EBC), também contribuiu para manter a CNV sob holofote. Pesa sobre a agência e sobre o Estado de São Paulo - do mesmo grupo da Agência Estado - o fato de outros veículos terem reproduzido notícias por eles produzidas. Além das matérias no próprio Estado de São Paulo (e no site Estadão), em outras três ocasiões o mesmo conteúdo foi reproduzido em outras mídias noticiosas. Já duas notícias da Agência Brasil foram veiculadas em dois outros jornais.

$\mathrm{Na}$ contabilização das notícias só aparece a rádio $C B N$, mas é preciso ressaltar que o clipping também incluiu matérias da página de internet da Rádio Eldorado. No entanto, como a Eldorado pertence ao grupo do Estado de São Paulo e as matérias foram reprodução do material publicado no site do Estadão, que subsidia a página da rádio, consideramos mais correto não levar em consideração na análise a duplicidade dessas notícias.

É possível destacar que os impressos diários ofertaram mais destaque às temáticas relativas à $\mathrm{CNV}-\mathrm{e}$ consequentemente à ditadura - do que os telejornais e os sites e portais não vinculados a impressos ou emissoras de rádio e TV (como o Yahoo Notícias! e o Terra). Já a revista semanal Veja publicou duas reportagens e a Istoé uma, o que é justificável pelo fato de a pesquisa ter se concentrado num período curto (uma semana).

\section{Tabela 2}

\begin{tabular}{|ll}
\hline Nome veículo & No Notícias \\
\hline Folha de S.Paulo & 9 \\
\hline O Globo & 9 \\
\hline Estadão & 8 \\
\hline Agência Brasil & 7 \\
\hline Estado de Minas & 6 \\
\hline G1 & 5 \\
\hline CBN & 4 \\
\hline iG & 2 \\
\hline Veja & 2 \\
\hline R7 & 2 \\
\hline Yahoo! Notícias & 1 \\
\hline Caros Amigos & 1 \\
\hline Zero Hora & 1 \\
\hline UOL & 1 \\
\hline Correio do Brasil & 1 \\
\hline Jornal Nacional & 1 \\
\hline Istoé & 1 \\
\hline Terra & 1 \\
\hline Jornal da Globo & 1 \\
\hline Jornal do Brasil & 1 \\
\hline Total: 64 & \\
\hline
\end{tabular}

$\mathrm{Na}$ grande maioria dos casos (34), as notícias foram vinculadas às editorias de política dos sites e portais, ainda que sob outra chancela (como Poder, como é chamada a editoria de política da Folha de São Paulo). As outras 30 matérias foram atreladas às editorias Brasil, País, Nacional e Cidadania (esta última muito
Segundo Traquina (2008), valoresnotícia são critérios de noticiabilidade usados na seleção dos acontecimentos, como forma de enquadrá- 
usada pela Agência Brasil), entre outras.

Entre os enquadramentos majoritários percebidos estão: o lugar de fala de autoridade atribuído à comissão, a tentativa de esclarecer sucintamente o que é uma comissão da verdade, as críticas à forma de trabalho da comissão e as revelações inéditas trazidas por ela. Nenhuma reportagem focou especificamente o Golpe de 1964, sendo este evento pouco referenciado, mas seus desdobramentos valorizados.

Principalmente nas matérias de balanço das atividades da CNV, de especulação sobre o que teria no relatório e de divulgação do relatório, percebe-se uma tendência a tentar explicar sucintamente do que se trata uma comissão da verdade. Contudo, raras foram as reportagens que abordaram com profundidade o papel desempenhado pelo colegiado, e, quando isso foi feito, poucas fontes foram ouvidas (normalmente apenas uma pessoa, principalmente ligada à área do direito, com conhecimento sobre a comissão) sem garantir a pluralidade e diversidade de opiniões necessárias ao conteúdo jornalístico.

É possível afirmar que, na cobertura em questão, houve tentativa de promover outro olhar sobre os crimes da ditadura. Contudo, mais do que preocupadas em desconstruir versões anteriormente disseminadas, as reportagens pareceram estar fundamentadas no "fato novo", ou seja, naquilo que não havia sido levantado anteriormente. $\mathrm{O}$ caso do ex-militar que somente agora resolveu contar abertamente o que presenciou (a morte de dois militantes de esquerda após serem presos) é um exemplo de que são privilegiados os fatos descobertos atualmente sem que se promova reflexão ou que se questione o que havia sido noticiado na época. As matérias contribuem para desmentir a versão oficial de 1968, que dizia que o casal de militantes havia morrido após a detonação de explosivos supostamente transportados por eles em um carro enquanto trafegavam pela BR-116. Mas o foco de todas as reportagens é o fato novo: a revelação do nome do comandante (Freddie Perdigão Pereira) que executou as duas vítimas e forjou o local de um acidente.

\section{Considerações finais}

Diante de um período tão curto de análise, é impossível estender os resultados alcançados a outros produtos midiáticos veiculados em ocasiões distintas e que envolveram a ditadura militar e a Comissão Nacional da Verdade. Mas ainda que exista esse limitador, acreditase que os indícios aqui apontados podem ser usados para análises futuras acerca da mesma temática com o intuito de delinear um mosaico da cobertura jornalística que atualmente retoma os 21 anos que o Brasil viveu sob regime autoritário.

Salta aos olhos o fato de entre 64 matérias veiculadas de 15 a 22 de maio de 2013 nenhuma ter sido oriunda de pauta desenvolvida pelas próprias redações (salvo raras exceções que foram as matérias voltadas a analisar um ano de atividades da CNV, e que, mesmo assim, é possível considerar que foram pautadas pelo calendário da comissão). Ou seja, em um cenário que envolveu os mais diversos produtos midiáticos disponibilizados na internet (englobando coberturas feitas pelas equipes dos próprios sites, mas também por jornais impressos, revistas, telejornais e rádios), a imprensa brasileira 
se demonstrou reativa. Mais que isso, mesmo tendo tantos assuntos a serem remexidos, o jornalismo investigativo e de indignação não foi priorizado, em detrimento do mero jornalismo factual. Nesse período, nenhuma matéria investigativa foi publicada e os dados e balanços que integram as reportagens foram disponibilizados pela $\mathrm{CNV}$ ou por comissões locais. Isso revela que as comissões da verdade são provocadoras do debate público e as grandes responsáveis por retornar com a temática da ditadura. Caso contrário, o envolvimento da sociedade com o assunto pela mediação do jornalismo ficaria restrito às raras reportagens especiais que vez ou outra ganham destaque nos noticiários.

Sem a provocação da mídia, muitas vezes, também há uma ausência de clamor público e ativo sobre este período da história, com raras exceções de famílias que perderam seus entes ou de alguns setores e instituições específicas da sociedade. Lembrando que a mídia tem um importante papel em processos de consolidação democrática e desenvolvimento do país e que investigar o passado para que os erros não se repitam é condição sine qua non para uma imprensa que se diz independente e libertária. Ajudar a construir, preservar e recontar a memória do país é, portanto, fator primordial para a imprensa, que deveria estar não só a reboque dos assuntos levantados pela Comissão Nacional da Verdade e pelas respectivas comissões estaduais e municipais.

Portanto, além das inúmeras atribuições e características descritas neste artigo para definir o que seria uma comissão da verdade, pode-se destacar o papel fundamental de afetar a compreensão social. Por isso, defende-se a relevância de incluir, na última definição elaborada por Priscilla Hayner, a responsabilidade das comissões em promoverem o debate público e pautarem a imprensa.

Também foi perceptível na semana de análise que os jornais impressos foram os que mais dedicaram espaço à temática, o que é compreensível diante da necessidade de se dedicar espaços maiores e que possam ser revistos para relembrar o interesse público do tema, com suas especificidades. Entre os assuntos que ganharam repercussão estão a possibilidade de revisão da lei de anistia e de que a comissão da verdade indique punição de perpetradores, o balanço e os principais resultados apontados pelo relatório de um ano de atividades da CNV. Isso indica novamente que o calendário da comissão agenda a imprensa, cuja cobertura demonstrou estar majoritariamente atrelada aos eventos celebratórios e midiáticos promovidos. O ponto positivo é o legado de que é possível promover diversidade de olhares sobre o complexo fenômeno da ditadura militar brasileira e acerca das narrativas midiáticas construídas. Ainda que no período em questão tenha sido verificado comportamento reativo por parte da impressa, defende-se que tal cobertura é válida diante da possibilidade de que, em vez dela, houvesse o silenciamento. 


\section{Referências bibliográficas}

BARDIN, Laurence. Análise de conteúdo. Lisboa: Edições 70, 2008.

BIROLI, Flávia (2009). Representações do golpe de 1964 e da ditadura na mídia: sentidos e silenciamentos na atribuição de papéis à imprensa, 1984-2004. Varia historia. vol. 25, n.41, Belo Horizonte Jan/Jun. pp.269-291. Disponível em: <http:// www.scielo.br/scielo.php? script=sci_arttext\&pid=S0104-87752009000100014>. Acesso em: 10 jan. 2014.

COMISSÃO NACIONAL DA VERDADE. Disponível em: <http://www.cnv.gov. br>. Acesso em: 1 set. 2012.

ENTMAN, Robert N. Framing: Toward Clarification of a Fractured Paradigm. Disponível em: <http://www.unc.edu/ fbaum/teaching/POLI891_Sp11/articles/JCommunication-1993-Entman.pdf>. Acesso em: 3 fev. 2012.

GITLIN, Todd. The whole world is watching: mass media in the making and unmaking of the new left. Berkeley: University of California Press, 1980.

GOFFMAN, Erving. Os quadros da experiência social: Uma perspectiva de análise. Petrópolis, RJ: Vozes, 2012.

HAYNER, Priscilla B. Unspeakable truths: Transitional Justice and the challenge of truth commissions. 2ed. New York: Routledge, 2011.

JURISPRUDÊNCIA DA CORTE INTERAMERICANA DE DIREITOS HUMANOS (1988). Caso Velásquez Rodríguez: Sentença de 29 de julho de 1988. Disponível em: < http://www.pge.sp.gov.br/centrodeestudos/bibliotecavirtual/ interamericano/2221caso.htm>. Acesso em: 10 jan. 2014.

MOTTA, Luiz Gonzaga. Análise pragmática da narrativa jornalística. In: LAGO, Cláudia; BENETTI, Márcia (orgs.) Metodologia de pesquisa em jornalismo. 2.ed. Petrópolis, RJ: Vozes, 2008.

PORTO, Mauro. Enquadramentos da mídia e política. In: Anais do XXVI Encontro Anual da Associação Nacional de Pós-Graduação e Pesquisa em Ciências Sociais (Anpocs), Caxambu- MG, 2002.

ROLLEMBERG, Denise. As Trincheiras da Memória: A Associação Brasileira de Imprensa e a ditadura (1964-1974). In: ROLLEMBERG, Denise; QUADRAT, 
Samantha Viz (org). A construção social dos regimes autoritários: Legitimidade, consenso e consentimento no Século XX. Vol. 2: Brasil e América Latina. Rio de Janeiro: Civilização Brasileira, 2010.

STAMPA, Inez Terezinha; SÁ NETTO, Rodrigo de. Arquivos da repressão e da resistência: comunicações do I Seminário Internacional Documentar a Ditadura. [Livro eletrônico]. Rio de Janeiro: Arquivo Nacional / Centro de Referência Memórias Reveladas, 2013.

TRAQUINA, Nelson. Teorias do jornalismo volume II: A tribo jornalística - uma comunidade interpretativa transnacional. Florianópolis: Editora Insular, 2.ed, 2008.

WAISBORD, Silvio. Watchdog Journalism in South America: News, Accountability, and Democracy. New York: Columbia University Press, 2000.

Este artigo e todo o conteúdo da Estudos em Jornalismo e Mídia estão

disponíveis em https://periodicos.ufsc.br/index.php/jornalismo

Estudos em Jornalismo e Mídia está sob a Licença Creative Commons 2.5 